\title{
ESCALAS DA EXCLUSÃO DIGITAL
}

\author{
SCALE OF DIGITAL EXCLUSION \\ ESCALAS DE LA EXCLUSIÓN DIGITAL \\ Antonio Bernardes - Universidade Estadual Paulista - Presidente Prudente - São Paulo - Brasil \\ antonio_h_bernardes@yahoo.com.br
}

\section{Resumo}

Ao analisar a distribuição e a organização dos objetos técnicos que compõem a rede Internet podemos considerá-las pela ótica de três totalidades imbricadas, com base no modo proposto por Milton Santos para a análise das redes, identificando as intencionalidades a elas atribuídas, o que leva ao processo de inclusão/exclusão socioespacial.

Palavras-chave: espaço, escalas geográficas, exclusão digital, exclusão social, internet.

\section{Abstract}

According to Milton Santos, we must analyze the distribution and organization of technical objects that makes up the Internet network from three interrelated totalities, in order to identify the intention attributed to them that leads to the process of socio-spatial inclusion or exclusion.

Key words: space, geographical scales, digital divide, social exclusion, internet network.

\section{Resumen}

Analizándose la distribución y la organización de los objetos técnicos que constituyen la red de Internet podremos considérala en tres totalidades integradas, como propuesto por Milton Santos para análisis de las redes, reconociendo las intencionalidades que les se atribuyen y que pueden conducir al proceso de inclusión/exclusión espacial.

Palabras clave: espacio, escalas geográficas, exclusión digital, exclusión social, internet.

\section{Introdução}

Algumas décadas atrás, dentre os serviços de telecomunicações analógicos existentes, o de maior popularidade era o de telefonia fixa, utilizado principalmente como meio de comunicação de voz. A sua implementação ocorreu em diferentes e longínquas áreas do Brasil, buscando atender o maior número de pessoas possível, inclusive aquelas que se localizavam em áreas rurais, onde a demanda dos usuários não garantia o retorno financeiro dos investimentos às operadoras pela implementação da infraestrutura necessária. Com a difusão e o desenvolvimento dos serviços de telecomunicação, as informações que eram transmitidas em formato analógico passaram para o digital, a ponto de, na década de 1990, tornar-se possível o uso público da rede Internet, que até então era restrita a algumas entidades militares ou governamentais. 
A difusão da Internet como meio de telecomunicação de uso público ocorreu pela reutilização da infraestrutura das redes telefônicas, as quais, no caso brasileiro, abrangiam boa parte do território nacional. Além disso, a sua consolidação sucede na medida em que ela é um meio de telecomunicação mais barato para o usuário final e mais rápido que a telefonia fixa.

Atualmente, a incorporação deste novo sistema de telecomunicação demanda grandes investimentos, pois exige a implementação de um conjunto de objetos técnicos que vai além daqueles utilizados no sistema de telefonia fixa, como, por exemplo, os servidores e o cabeamento de fibra ótica para transmissão de dados em alta velocidade. A utilização da Internet, com transmissão de dados em alta velocidade, continua restrita a algumas áreas que possuem os objetos técnicos necessários para sua efetivação. Assim, os usuários e as instituições distantes dos locais onde se concentram estes objetos, sobretudo dos provedores locais, se quiserem ter acesso à rede devem arcar com um custo relativamente alto.

A ampliação da infraestrutura de acesso a Internet é necessária para incluir áreas, pessoas e instituições nesta rede de telecomunicação, mas também para promover a alfabetização digital, ou seja, para que as pessoas se capacitem a utilizar as diversas mídias eletrônicas de acordo com suas necessidades, tornando-se beneficiários ativos das informações que são veiculadas pela Internet.

Deste modo, no intuito de analisar os modos de exclusão digital e/ ou exclusão social, provocados por este novo sistema de telecomunicação, podemos indicar três âmbitos de análise das redes, conforme proposto por Santos (1996, p. 270):

O mundo aparece como primeira totalidade, empiricizada por intermédio das redes. [...] A segunda totalidade é o território, um país e um Estado - uma formação socioespacial -, totalidade resultante de um contrato e limitada por fronteiras. O lugar é a terceira totalidade, onde os fragmentos da rede ganham uma dimensão única e socialmente concreta [...].

Desenvolvendo a proposição de Santos, buscaremos traçar alguns indicativos dos modos como ocorre a exclusão/inclusão digital. Para a primeira e a segunda totalidade buscaremos identificar e entender o modo de distribuição e organização dos objetos técnicos que a constituem, tanto em âmbito mundial como no âmbito restrito de um país, no caso, o Brasil. 
Para a terceira totalidade, buscaremos abordar o processo e os modos de exclusão e/ou inclusão precária dos lugares e de seus usuários.

\section{A primeira e a segunda totalidade da exclusão digital}

O mundo, como primeira totalidade para a rede de Internet, pode ser entendido pela distribuição e organização dos objetos técnicos que a constituem e que podem ser arrolados em conformidade com sua importância para este sistema de telecomunicação. Os backbones definem a qualidade do sistema e os locais de sua densidade, ou melhor, a velocidade e a integridade das informações veiculadas; os servidores indicam a distribuição das informações; os cabos, as antenas e os modems caracterizam a densidade e a qualidade da informação direcionada para dado local; e o computador pessoal é o meio pelo qual os usuários utilizam o sistema.

Por meio dos backbones, que são a espinha dorsal da rede Internet, todos os dados dos usuários da rede transitam; são, também, responsáveisl por enviar e receber dados entre as cidades ou para fora de determinado país. Por constituir a rede principal, o backbone transmite informações de modo muito mais rápido do que as várias redes menores, que se conectam a ele e as repassa aos destinatários particulares. Já os servidores são os objetos técnicos que têm como atribuição geral receber, controlar e armazenar os dados veiculados na Internet, geralmente oriundos dos computadores pessoais. Há vários tipos de servidores de Internet, cada qual com uma função específica.

Um dos modos de mensurar a capacidade de transmissão de dados dos backbones é identificar a quantidade de usuários com acesso à Internet de banda larga em determinada área. Se esses usuários são numerosos, necessariamente haverá maior concentração de servidores e cabos com alta velocidade de transmissão.

Como podemos notar pela leitura da Tabela 1, boa parte dos países com grande quantidade de assinantes de banda larga é constituída por aqueles considerados economicamente desenvolvidos, destacando-se o Brasil, que se situa em $11^{\circ}$ lugar, com 6.417.000 assinantes. Todavia, no Brasil, apenas 3,4\% da população tem acesso à Internet de banda larga, ou seja, apenas uma faixa muito estreita da população utiliza este tipo de serviço. Este número de assinantes, no entanto, expressa uma quantidade expressiva no cenário mundial. 
Tabela 1 - Países com maior quantidade de assinantes de banda larga (2007)

\begin{tabular}{l|c|c}
\hline País & $\begin{array}{c}\text { Assinantes de banda } \\
\text { larga }\end{array}$ & $\begin{array}{c}\text { Relação de assinantes de banda larga } \\
\text { com a população absoluta }\end{array}$ \\
\hline Estados Unidos da América & 66.213 .257 & $21.9 \%$ \\
\hline China & 48.500 .000 & $3.7 \%$ \\
\hline Japão & 27.152 .349 & $21.1 \%$ \\
\hline Alemanha & 17.472 .000 & $21.2 \%$ \\
\hline Coreia do Sul & 14.042 .728 & $27.4 \%$ \\
\hline Reino Unido & 13.957 .111 & $23.1 \%$ \\
\hline França & 13.677 .000 & $22.3 \%$ \\
\hline Itália & 9.427 .300 & $15.8 \%$ \\
\hline Canadá & 7.675 .533 & $23.7 \%$ \\
\hline Espanha & 7.505 .456 & $16.7 \%$ \\
\hline Brasil & $\mathbf{6 . 4 1 7 . 0 0 0}$ & $3.4 \%$ \\
\hline Holanda & 5.388 .000 & $32.8 \%$ \\
\hline Taiwan & 4.505 .800 & $19.6 \%$ \\
\hline Austrália & 3.939 .288 & $18.8 \%$ \\
\hline México & 3.728 .150 & $3.5 \%$ \\
\hline Turquia & 3.632 .700 & $4.8 \%$ \\
\hline Rússia & 2.900 .000 & $2.0 \%$ \\
\hline Polônia & 2.640 .000 & $6.9 \%$ \\
\hline Índia & 2.520 .000 & $0.2 \%$ \\
\hline Suécia & 2.478 .003 & $27.2 \%$ \\
\hline Fon & & \\
\hline
\end{tabular}

Fonte: $<$ http://www.Internetworldstats.com/dsl.htm $>$.

Como podemos notar pela leitura da Tabela 1, boa parte dos países com grande quantidade de assinantes de banda larga é constituída por aqueles considerados economicamente desenvolvidos, destacando-se o Brasil, que se situa em $11^{\circ}$ lugar, com 6.417.000 assinantes. Todavia, no Brasil, apenas 3,4\% da população tem acesso à Internet de banda larga, ou seja, apenas uma faixa muito estreita da população utiliza este tipo de serviço. Este número de assinantes, no entanto, expressa uma quantidade expressiva no cenário mundial.

Por outro lado, se considerarmos os diferentes modos de acesso à Internet, não nos restringindo apenas à banda larga (considerando, por exemplo, o acesso discado, internet sem fio, via rádio etc.), é possível per- 
ceber que países considerados como de economia emergente possuem uma grande quantidade de usuários, embora representem, ainda, em números relativos, uma faixa estreita de sua população total, como demonstrado na Tabela 2.

Tabela 2 - 0s 10 países com maior quantidade de usuários de Internet (2009)

\begin{tabular}{l|c|c}
\hline País & Usuários de Internet & $\begin{array}{c}\text { Relação de usuários de Internet com a } \\
\text { população absoluta }\end{array}$ \\
\hline China & 298.000 .000 & $22.4 \%$ \\
\hline Estados Unidos da América & 227.190 .989 & $74.7 \%$ \\
\hline Japão & 94.000 .000 & $73.8 \%$ \\
\hline Índia & 81.000 .000 & $7.1 \%$ \\
\hline Brasil & 67.510 .400 & $34.4 \%$ \\
\hline Alemanha & 55.221 .183 & $67.0 \%$ \\
\hline Reino Unido & 43.753 .600 & $71.8 \%$ \\
\hline França & 40.858 .353 & $65.7 \%$ \\
\hline Rússia & 38.000 .000 & $27.0 \%$ \\
\hline Coreia do sul & 36.794 .800 & $76.1 \%$ \\
\hline
\end{tabular}

Fonte: <http://www.Internetworldstats.com/top20.htm>.

Como se vê, são os países de economia desenvolvida e aqueles de economia emergente que possuem a maior quantidade de usuários de Internet no mundo; os primeiros possuem maior quantidade de assinantes de banda larga em relação aos segundos, o que denota uma distribuição desigual dos objetos técnicos e das relações possíveis desses objetos com os habitantes de um país.

Por meio de uma representação cartográfica (Mapa 1) podemos aproximar ainda mais os dados trabalhados com o tema abordado.

Preliminarmente, nota-se que os objetos técnicos que compõem a rede de Internet são distribuídos no mundo de modo seletivo. Para Castells (1996, p.98) este processo consistiria numa forma de exclusão social, visto que

exclusão social é o processo pelo qual determinados grupos e indivíduos são sistematicamente impedidos de acesso a posições que lhes permitiriam uma existência autônoma dentro dos padrões sociais determinados por instituições e valores inseridos em um dado contexto. (Grifo nosso) 
Mapa 1 - Densidade de usuários de Internet no mundo - 2009

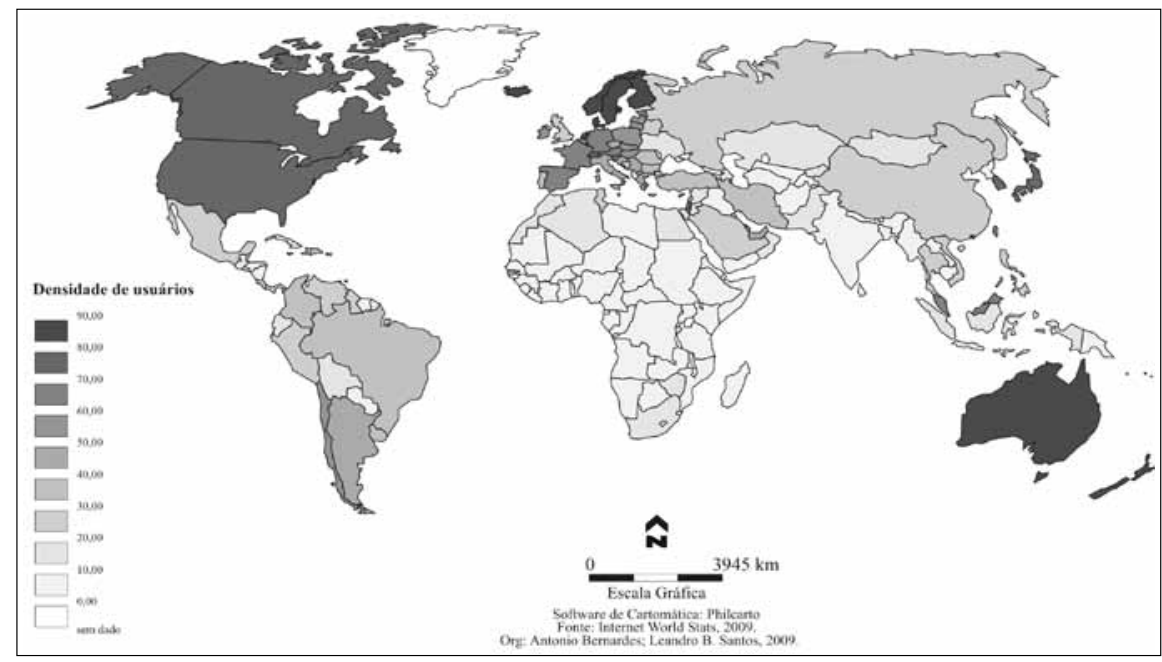

No período técnico-científico informacional, como Milton Santos denomina o atual período, a ideologia da velocidade e o poder da informação ganham contornos expressivos e os espaços pouco dotados do conteúdo técnico-científico informacional acabam por se tornar opacos aos ditames do atual período, ficando à margem do processo de desenvolvimento tecnológico e de investimentos de capital. A exclusão social tem a capacidade de atingir os territórios de forma que, sob algumas condições, países, regiões, cidades e bairros inteiros são excluídos ou incluídos precariamente, assim como parte de sua população, quando considerado determinado sistema técnico.

Os espaços opacos ou excluídos da rede de Internet no mundo estão concentrados, principalmente, no continente africano, e em alguns países do sul da Ásia e norte da Oceania. Atualmente, a exclusão digital se constitui como uma das dimensões da exclusão social e possui como conteúdo as relações mediadas eletronicamente, que a caracterizam.

No Brasil, a exclusão digital pode ser evidenciada pela concentração dos backbones de uso comercial e aqueles destinados à pesquisa, como é o caso da Rede Nacional de Ensino e Pesquisa (RNP) ${ }^{1}$ nas áreas de maior desenvolvimento econômico, como a Região Sudeste e o Distrito Federal, com ramificações de menor velocidade para boa parte das capitais brasileiras, como pode ser visto no mapa 2. 
Mapa 2 - Distribuição dos backbones e fluxo de dados no Brasil - 2009

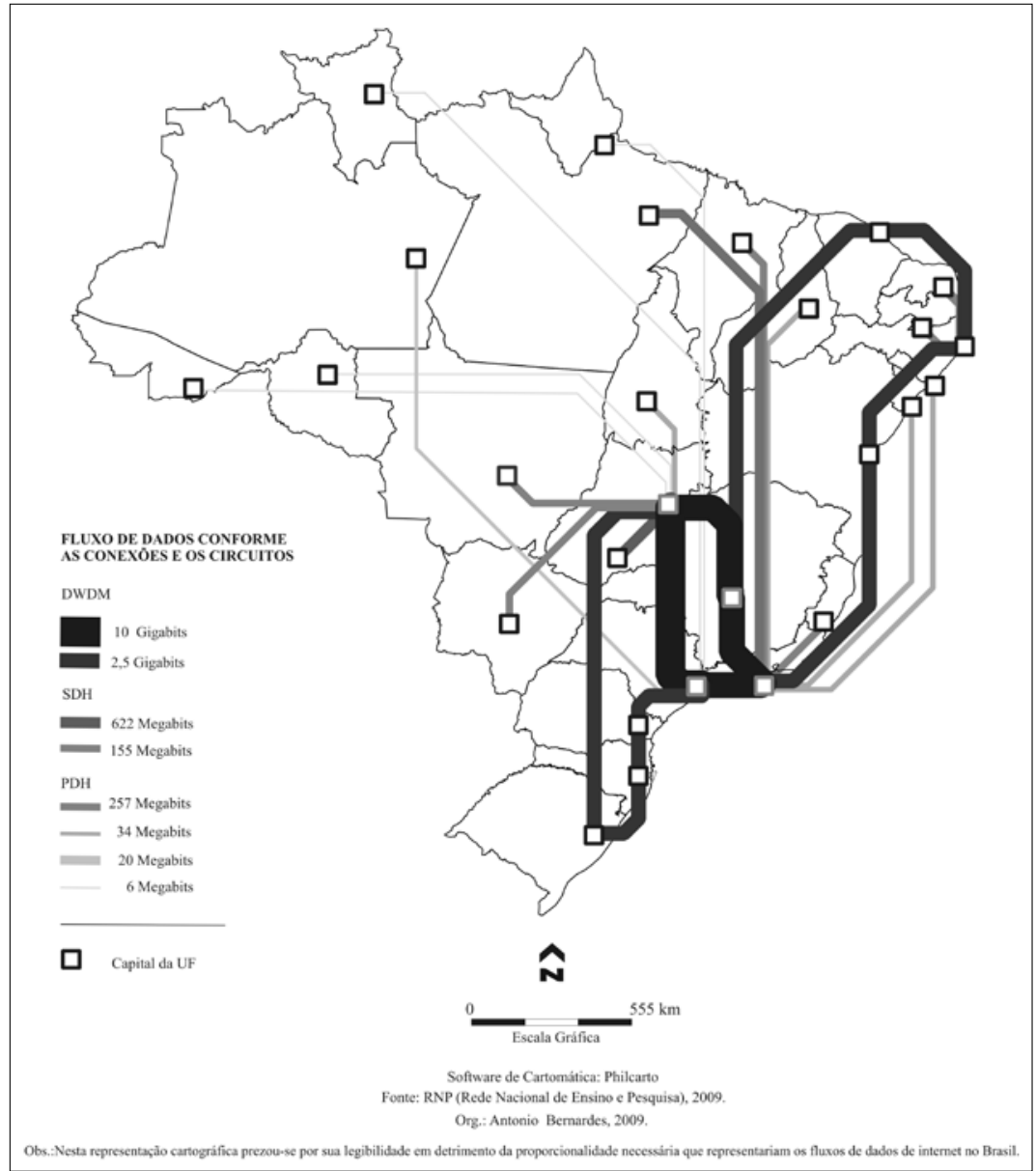

DWDM (Dense Wavelenght Division Multiplexing), SDH (Synchronous Digital Hierarchy) e PDH (Plesiochronous Division Hierarchy) são diferentes tipos de tecnologias de transporte de dados digitais, ou seja, expressam a forma pela qual os pacotes de dados, que contêm as informações, são enviados numa determinada rede. A primeira e a segunda tecnologia possuem maior capacidade de transmissão, são mais velozes e mais usuais em relação à PDH, tecnologia obsoleta e mais lenta para transmissão de dados digitais. 
As cidades de São Paulo, Rio de Janeiro, Belo Horizonte e Distrito Federal contam com a tecnologia DWDM, com velocidade de transmissão de dados muito superior a outros pontos da rede nacional (por volta de 10 Gbps ou 10.240 Mbps). Do mesmo modo, as capitais dos Estados da Região Sul e do Nordeste também se utilizam da tecnologia DWDM, todavia com velocidade quatro vezes menor do que a utilizada no primeiro grupo de estados brasileiros considerado (2,5 Gbps). As demais regiões utilizam, em sua transmissão de dados, tecnologias inferiores à DWDM, o que acarreta menor velocidade e menor densidade das informações veiculadas (variando de 16 a 1706 vezes menos).

Outros dados importantes acerca da questão: 58\% dos servidores e cabeamentos de alta velocidade da rede secundária derivada dos backbones estão na Região Sudeste, sendo $12 \%$ no município de São Paulo e $8 \%$ no Estado do Rio de Janeiro. ${ }^{2}$ Por este backbone também se realiza a conectividade internacional para tráfego de Internet comercial e para a rede destinada a pesquisas científicas.

\section{A terceira totalidade da exclusão digital}

A inclusão/exclusão digital na primeira e na segunda totalidade foi considerada conforme a distribuição e organização dos objetos técnicos que constituem a rede de Internet no mundo e no território nacional, no caso o Brasil.

Na análise da terceira totalidade das redes, é possível refletir acerca do modo como as intencionalidades atribuídas aos objetos técnicos, que compõem a rede de Internet, são estabelecidas em sua relação com os homens, visto que apenas na terceira totalidade da rede, ou seja, no âmbito do cotidiano e do lugar, é que as ações ensejadas ou as intencionalidades atribuídas ao meio, na concepção de determinado sistema técnico, ganham concretude (Santos, 1996).

Cada lugar é, ao mesmo tempo, processo e resultado da contradição de uma lógica global e de uma lógica local, sendo a expressão material dos conflitos entre as ações dos atores hegemônicos e hegemonizados. Nas palavras de Milton Santos (1996, p. 322):

No lugar - um cotidiano compartido entre as mais diversas pessoas, firmas e instituições - cooperação e conflito são a base da vida em comum. Porque cada qual exerce uma ação própria, a vida social 
se individualiza; e porque a contiguidade é a criadora de comunhão, a política se territorializa, com confronto entre organização e espontaneidade. O lugar é o quadro de uma referência pragmática ao mundo, do qual lhe vêm solicitações e ordens precisas de ações condicionadas, mas é também o teatro insubstituível das paixões humanas, responsáveis, através da ação comunicativa, pelas mais diversas manifestações da espontaneidade e criatividade.

A lógica global funda as duas primeiras totalidades das redes. Seus parâmetros são a razão técnica e operacional e o cálculo das funções dos objetos. A lógica local funda a terceira totalidade das redes, cujos parâmetros são a sociabilização, a cooperação e as emoções humanas, dimensões caracterizadoras do lugar. É no lugar que os objetos técnicos se apresentam como uma condição da ação humana, seja como uma estrutura de controle, como um limite à própria ação, ou como certo instrumento capaz de dinamizar a realização das tarefas cotidianas e de ampliar a capacidade de intervenção da própria ação humana. É sempre no lugar, como terceira totalidade da rede de Internet, que o processo de organização dos objetos técnicos, que ocorrem nas mais variadas instâncias que a constituem, entrar de fato em contato com o usuário sob a forma de relação homem/máquina (neste caso, o computador pessoal).

É pela relação entre os diferentes lugares, com maior ou menor aporte técnico - o que caracteriza a rede de Internet -, é que podemos definir o grau de inclusão/exclusão digital de um lugar. A diferenciação ocorre pela implementação dos objetos técnicos e suas respectivas atribuições em determinado lugar, o que o distingue de outros. Muitas vezes, as atribuições dos atores hegemônicos impostas aos lugares por meio dos objetos técnicos são estranhas aos lugares e aos homens, pois estão baseadas, principalmente, numa lógica mercadológica.

Privilegiar certos lugares com maior conteúdo técnico e informacional em detrimento de outros pode ser considerado como uma expressão do modo capitalista de produção, que, quando inclui certos lugares, pode incluir outros precariamente, ou mesmo excluí-los, uma vez que o que interessa é o lucro e as repostas positivas às atribuições previstas para esses lugares. Lugares pobres, sem recursos mínimos, sem estrutura para possibilitar a telecomunicação pela Internet, podem caracterizar exclusão digital quando se leva em conta a distribuição dos objetos técnicos, mas não quanto ao processo produtivo que o fomenta, na medida em que pode ser alvo de outras formas de especulação. 
Este processo, consubstanciado no lugar, coloca os homens e o meio - e as relações entre eles - como se estivessem num outro período técnico, que pode não corresponder ao sistema-mundo vigente, ou seja, ao modo de produção e ao sistema técnico dominante, mas o complementa. Se determinado lugar não possui aporte técnico para promover as relações de interface, isto não exclui completamente os homens deste tipo de relação; ou melhor, o exclui apenas enquanto uma relação efetiva, pois para uma relação potencial, baseada na ideologia e no fetiche, é possível consumir a ideia de relação de interface.

Sem dúvida, atualmente, há lugares que são destituídos de quaisquer objetos técnicos que possibilitem a realização de relações de interface pelo uso da Internet. Sem rede de telefonia fixa, móvel ou por satélite, que possibilitariam uma conexão à Internet, no limite, poder-se-ia falar de um modo de exclusão social desse lugar e de sua população, caso se considere somente a estrutura e as relações possíveis por este meio de telecomunicação. Contudo, há outros modos de exclusão mais sutis, quando o lugar possui os objetos técnicos que possibilitam a relação de interface pela Internet, mas certas pessoas não dispõem dos meios econômicos para efetivar esta relação. Neste caso estaríamos diante de alguém com fraca integração social.

A primeira implicação deste modo de ver a questão é que o "excluído”, sendo aquele que se encontra desintegrado, é uma pessoa em desvantagem na sua relação com o lugar. Para as relações mediadas pela Internet este é um fenômeno de fácil ocorrência, mas não ocorre o mesmo nas relações entre as pessoas e os lugares, quando não destacamos certo sistema técnico. Pensar em uma população ou em lugares "excluídos" seria pressupor uma total ausência de vínculos espaciais e sociais, o que é uma condição de difícil verificação. Há, porém, o processo de exclusão, como fragilização de vínculos sociais e de ruptura de alguns deles, o que pode desencadear outras possibilidades de análise, sobretudo quando nos referimos a uma rede técnica específica e a suas relações. Por ora, nos restringiremos a considerar estas pessoas, com dificuldades pessoais de integração, quando são tomadas em consideração suas relações mediadas pela Internet, como pessoas de pouca integração social, servindo-nos de algumas considerações do sociólogo José de Souza Martins (1997, p. 14):

[...] rigorosamente falando, não existe exclusão: existe contradição, existem vítimas de processos sociais, políticos e econômicos exclu- 
dentes; existe o conflito pelo qual a vítima dos processos excludentes proclama seu inconformismo, seu mal-estar, sua revolta, suas esperanças, sua força reivindicativa e sua reivindicação corrosiva. Essas reações [...] constituem o imponderável de tais sistemas, fazem parte deles ainda que os negando.

De acordo com o que afirma Martins, não existe exclusão social. O que há é uma contradição causada pelos processos sociais, políticos e econômicos, processos engendrados de acordo com a lógica do modo capitalista de produção, ou seja, que representam os atores hegemônicos que estão no poder. De certa forma, a população pobre participa desse processo, mesmo que de modo precário, o que não significa, necessariamente, exclusão.

No mesmo sentido, para Demo (1998) não existe condição de exclusão absoluta, mas formas degradadas de inclusão, uma vez que a exclusão é um produto da sociedade, constituindo uma integração contraditória de certa parte da população à sociedade.

A exclusão é uma forma de inclusão, ou seja, uma maneira de exercer uma função dialética no sistema [...]. O que mais a exclusão social escancara é a luta desigual, a concentração de privilégios, a repartição injusta dos espólios de uma sociedade falida. (Demo, 2003, p. 105)

O processo de inclusão precária a que Martins se refere e que Demo reforça constitui uma perspectiva de análise mais adequada quando se busca levar em conta o homem em determinado contexto social, ou seja, quando se reconhece que um dos modos como o homem se integra socialmente está atrelado ao seu acesso a determinados objetos técnicos. No entanto, isto só aparentemente o exclui, porque o que ocorre de fato é um processo contraditório inerente ao modo capitalista de produção. $\mathrm{O}$ homem, segundo esta compreensão, insere-se precariamente nas relações sociais de produção e de consumo.

Esta abordagem permite que uma compreensão das contradições internas observadas na terceira totalidade de análise das redes, na medida em que percebemos que não é o fato de determinado homem deter o objeto técnico (no caso o computador pessoal e acesso à rede de Internet) que o coloca como incluído digital. O que pode se evidenciar em muitos casos é um processo de inclusão precária, quando não há o domínio da linguagem de navegação na Internet. Mesmo em países economicamente desen- 
volvidos, vastas camadas sociais não conseguem se inserir digitalmente com autonomia. Usam produtos digitais como consumidores, mas não se dispõem a desenvolver habilidades digitais de manejo próprio. ${ }^{3}$

O analfabetismo digital vai se tornando, possivelmente, o pior de todos. Enquanto outras alfabetizações são já mero pressuposto, a alfabetização digital significa habilidade imprescindível para ler a realidade e dela dar minimamente conta, para ganhar a vida e, acima de tudo, ser alguma coisa na vida. Em especial, é fundamental que o incluído controle sua inclusão. (Demo, 2005)

A discriminação digital pode ir além daquela de ordem material, de acesso a equipamentos; com pouco domínio da linguagem informacional, qualquer pessoa está despreparada para os desafios do atual período. E esse domínio vai além do simples manuseio da máquina. Embora possa saber lidar com ela, se não sabe ler seus conteúdos, no sentido de compreender, interpretar, reconstruir, não sabe, enfim, pensar os desafios de uma sociedade e economia informacionais.

\section{Diálogo final}

No que se refere à primeira e segunda totalidade de compreensão da rede de Internet, notamos que determinados lugares com menor conteúdo característico do período técnico-científico informacional podem ser considerados excluídos em sua relação com outros meios. Por outro lado, ao levarmos em conta as considerações de Martins (1997) e Demo (2005), o que se nota é que em alguns lugares pode ocorrer uma inclusão precária das pessoas que têm poucas condições de se inserir no contexto do mundo globalizado.

Ao construir um discurso considerando a perspectiva desenvolvida pelos atores hegemônicos, ou melhor, as ações desenvolvidas pelos atores hegemônicos, que selecionam determinados lugares em detrimento de outros para a implementação de objetos técnicos que vão permitir maior e melhor acesso à Internet, acabamos por desenvolver os pressupostos do processo de exclusão social e digital. Todavia, se estamos considerando que a exclusão é um processo e não um produto social, cabe reconhecer que há diferentes graus de exclusão ou de inclusão. Nada está completamente alheio ao que se denomina "sistema-mundo". Meios, instituições e pessoas que não estão bem dispostos para o sistema hegemônico de pro- 
dução podem configurar outros sistemas marginais que desenvolvem as contradições próprias. Como frisou Milton Santos (1996), as relações horizontais desenvolvidas nessas condições, tão características dos espaços opacos, acabam se revelando um modo de integração social.

Como o processo dinâmico e contraditório das duas primeiras totalidades se manifesta concretamente na terceira totalidade, as proposições de Demo e Martins podem ser instrumentos úteis para compreensão da "exclusão" digital. Por meio do conceito de inclusão precária é possível explorar com mais clareza uma perspectiva que leve em conta o homem particular em sua relação com o mundo. Mesmo estando as pessoas em lugares que possuem o aporte técnico necessário para se estabelecer relações pela Internet, podem estar incluídas apenas precariamente. $\mathrm{Ou}$, ainda, as que se encontram em lugares que não dispõem da própria infraestrutura necessária para acessar a rede podem consumir essa relação em sua potencialidade, ideológica e fetichizada; nessa forma ela não se propaga mais rápido que a telecomunicação oriunda deste sistema, mas é mais fluida e chega a lugares e a pessoas que a telecomunicação não alcançaria. Outra categoria diferente é a daqueles usuários que possuem tanto o computador pessoal quanto o acesso à Internet, mas que não são "alfabetizados" digitalmente, possuindo certa resistência à informatização com que hoje convivem; também esses estão incluídos precariamente.

Entendemos que compreender o processo de inclusão/exclusão e inclusão precária nas relações mediadas pela Internet, como uma expressão social, foi possível por buscarmos a articulação das três totalidades das redes, e por diferenciar (e não tratar como sinônimos) os conceitos de pobreza e exclusão social. Afinal, a precariedade está no modo como o homem se relaciona com o mundo em sua volta, e apenas a presença ou mesmo a aquisição de um objeto técnico não o faz um incluído fluente.

\section{Notas}

1 A RNP expõe, em seu sítio eletrônico <http://www.rnp.br/backbone>, a rede de Internet denominada "Rede Ipê", que se destina à permuta científica entre as diversas instituições de ensino e pesquisa do Brasil, assim como as redes com destinação comercial. Neste sítio eletrônico, pelo link <http://www.rnp.br/ceo/ trafego/panorama.php>, é possível visualizar o fluxo de dados em tempo real dos principais backbones no Brasil.

2 Para maiores detalhes sobre a questão, cf. Gomes, 2002.

3 Um neologismo que expressa essa ideia é analfabite. 


\section{Referências}

CASTELLS, Manuel. Fim do milênio. São Paulo. Paz e Terra, 1996.

DEMO, Pedro. Charme da exclusão social. Campinas: Autores Associados, 1998.

DEMO, Pedro. Pobreza da pobreza. Petrópolis: Vozes, 2003.

DEMO, Pedro. Inclusão digital - cada vez mais no centro da inclusão social. Inclusão social, v.1, n.1, 2005. Disponível em: < http://revista.ibict.br/inclusao/index. php/inclusao/article/view/4/7>. Acesso em: 6 jul. 2009.

GOMES, Elisabeth. Exclusão digital: um problema tecnológico ou social? Rio de Janeiro: Trabalho e Sociedade, ano 2, n. especial, dez 2002. Disponível em: <http:// www.radio.faced.ufba.br/twiki/pub/GEC/RefID/Elisabeth_Gomes_ED.pdf >. Acesso em: 6 jul. 2009.

INTERNET WORLD STATS. Broadband Internet statistics top world countries with highest Internet broadband subscribers in 2007. Disponível em: <http://www. Internetworldstats.com/dsl.htm>. Acesso em: 8 jul. 2009.

INTERNET WORLD STATS. Top 20 countries with highest number of Internet users. Disponível em: <http://www.Internetworldstats.com/top20.htm>. Acesso em: 6 jul. 2009.

MARTINS, José de Souza. Exclusão social e a nova desigualdade. São Paulo: Paulus, 1997.

REDE NACIONAL DE ENSINO E PESQUISAS. Rede Ipê. Disponível em: <http:// www.rnp.br/backbone>. Acesso em: 8 jul. 2009.

SANTOS, Milton. A natureza do espaço. Técnica e tempo. Razão e emoção. São Paulo: Hucitec, 1996.

Antonio Bernardes - Doutorando em geografia pela Universidade Estadual Paulista/FCT e pesquisador/ bolsista pela FAPESP. 